\title{
Insulin-like growth factor-1 protects against prion peptide-induced cell death in neuronal cells via inhibition of Bax translocation
}

\author{
YANG-GYU PARK ${ }^{1}$, JAE-KYO JEONG ${ }^{1}$, MYUNG-HEE MOON ${ }^{1}$, JU-HEE LEE ${ }^{1}$, YOU-JIN LEE ${ }^{1}$, \\ JAE-WON SEOL ${ }^{1}$, SHANG-JIN KIM ${ }^{1}$, SEOG-JIN KANG ${ }^{2}$ and SANG-YOUEL PARK ${ }^{1}$ \\ ${ }^{1}$ Korea Zoonoses Research Institute, Bio-Safety Research Institute, College of Veterinary Medicine, \\ Chonbuk National University, Jeonju, Jeonbuk 561-756; ${ }^{2}$ Technology Service Division, National Institute of \\ Animal Science, Rural Development Administration, Suwon, Gyeonggi-do 441-706, Republic of Korea
}

Received May 16, 2012; Accepted June 28, 2012

DOI: $10.3892 / \mathrm{ijmm} .2012 .1087$

\begin{abstract}
Insulin-like growth factor-1 (IGF-1) is one of the most important components of bovine colostrum. It exhibits antiapoptotic and antioxidative activities. Prion diseases are neurodegenerative disorders caused by cell death through mitochondrial dysfunction and increasing generation of reactive oxygen species (ROS). This study examined the protective effect of IGF-1 on residues 106-126 of the cellular prion protein [PrP (106-126)]-mediated mitochondrial neurotoxicity and oxidative stress. In SH-SY5Y human neuronal cells, treatment with PrP (106-126) decreased the cell viability and IGF-1 pretreatment markedly blocked the PrP (106-126)-induced neuronal cell death. IGF-1 inhibited PrP (106-126)-induced intracellular ROS generation and mitochondrial oxidative stress. In addition, IGF-1 blocked the translocation of the Bax protein to the mitochondria induced by $\operatorname{PrP}$ (106-126). These results demonstrate that IGF-1 protects neuronal cells against PrP (106-126)-mediated neurotoxicity through an antioxidative effect and blockage of mitochondrial Bax translocation. The results also suggest that regulation of IGF-1 secretion may have a therapeutic potential in the management of mitochondrial dysfunction and oxidative stress-induced neurodegeneration.
\end{abstract}

\section{Introduction}

Prion diseases or transmissible spongiform encephalopathies (TSEs) are a group of animal and human brain diseases that are uniformly fatal and often characterized by a long incubation period and spongiform degeneration, multifocal neuropathologic picture of neuronal loss and neuronal death (1). Prion diseases are peculiar in that they are caused by an

Correspondence to: Professor Sang-Youel Park, Korea Zoonoses Research Institute, Bio-Safety Research Institute, College of Veterinary Medicine, Chonbuk National University, Jeonju, Jeonbuk 561-756, Republic of Korea

E-mail: sypark@chonbuk.ac.kr

Key words: insulin-like growth factor-1, prion protein (106-126), prion disease, $\mathrm{Bax}$ infectious agent, prion, whose main component is an abnormal isoform (PrPSc) of prion protein ( $\mathrm{PrP})(2)$. A synthetic peptide similar to sequence 106-126 of human [PrP (106-126)] induces apoptosis in primary rat hippocampal cultures (3). PrP (106-126), which is composed of amino acid sequence 106-126 of PrP, has been reported to induce apoptosis in a variety of cells (4). PrP (106-126) has been used to explore the neurotoxic mechanisms underlying prion disorders and has been demonstrated to induce mitochondria dysfunction (3).

Mitochondria fulfill various important roles in biosynthetic pathways, cellular redox homeostasis, cellular energetics, cellular differentiation and regulation of programmed cell death (5). Mitochondrial dysfunction caused by abnormal regulation of mitochondrial dynamic proteins may lead to neuropathological changes in prion diseases (6). In addition, mitochondrial dysfunction caused by translocation of the bax protein into the mitochondrial membrane and oxidative stress gives rise to neurodegeneration in prion disease $(7,8)$. Mitochondrial inhibitors protect neuronal cells from oxidative stress-induced cell death (9). An important effect of mitochondrial dysfunction is reactive oxygen species (ROS) generation (10).

Oxidative stress results from increased content of ROS (11). Oxidation of the mitochondrial permeability transition pores by ROS may contribute to cytochrome $c$ release due to disruption of the mitochondrial membrane potential (12). Oxidative stress leads to the intracellular production of ROS (13). Hence, oxidative stress can cause irreversible cellular damage since intracellular defense mechanisms are depleted and therefore cannot protect cells against ROS-mediated damage (13). In particular, ROS are recognized as crucial mediators of biological responses (14), including neurodegenerative disorders by misfolded protein (4). PrP contributes to the neuronal loss that occurs in prion disorders, through mechanisms involving modulation of cellular oxidation pathways (4).

Previous reports indicated that insulin-like growth factor (IGF) signaling can reduce oxidative stress in neurodegenerative disorders (15). Insulin-like growth factor-1 (IGF-1) is a multifunctional peptide that is structurally similar to insulin (16) and which is essential for normal fetal and postnatal growth, development, metabolism and apoptosis 
in mammals (16). IGF-1 is a trophic hormone with multiple neuroprotective actions (17). IGF-1 has salutary effects on mitochondria. However, the molecular mechanism of IGF-1-mediated neuronal survival is only beginning to be understood. Moreover, the pathogenesis of a number of neurodegenerative diseases is attributed to IGF-1 deficiency (18). IGF-1 has a neuroprotective effect via regulation of the serine kinase Akt that forms part of the canonical IGF-I pro-survival signaling pathway (17) and which is altered in neurodegenerative diseases including Huntington's disease and spinocerebellar ataxia (19).

We hypothesized that IGF-1 prevents oxidative stress and neuronal cell death. In the present study we investigated this hypothesis and found that IGF-1 treatment prevents prion-mediated mitochondrial dysfunction and neurotoxicity in neuronal cells. We tested whether IGF-1 prevents neuronal cell death by $\operatorname{PrP}$ (106-126) and assessed the therapeutic value of IGF-1 in the treatment of neurodegenerative disorders.

\section{Materials and methods}

Cell culture. The SH-SY5Y human neuroblastoma cell line was obtained from the American Type Culture Collection (ATCC, Rockville, MD, USA). Cells were cultured in Minimum Essential Medium (MEM; Invitrogen Life TechnologiesGibco-BRL, Grand Island, NY, USA) that contained $10 \%$ fetal bovine serum (FBS; Invitrogen Life TechnologiesGibco-BRL) and penicillin-streptomycin (both $100 \mathrm{U} / \mathrm{ml}$ ) in a humidified incubator maintained at $37^{\circ} \mathrm{C}$ and $5 \% \mathrm{CO}_{2}$.

Reagents. IGF-1 was purchased from Sigma-Aldrich (St. Louis, MO, USA). Antioxidant agents [glutathione (GSH) and $\mathrm{N}$-acetylcysteine (NAC)] were purchased from Sigma-Aldrich.

$\operatorname{PrP}$ (106-126) treatment. Synthetic PrP (106-126) (sequence, Lys-Thr-Asn-Met-Lys-His-Met-Ala-Gly-Ala-Ala-Ala-AlaGly-Ala-Val-Val-Gly-Gly-Leu-Gly) was synthesized by Peptron (Seoul, Korea). The peptide was dissolved in sterile dimethylsulfoxide (DMSO) at a concentration of $10 \mathrm{mM}$ and stored at $-80^{\circ} \mathrm{C}$.

Western blot analysis. SH-SY5Y was lysed in a buffer containing $25 \mathrm{mM}$ HEPES; pH 7.4, $100 \mathrm{mM} \mathrm{NaCl}, 1 \mathrm{mM}$ EDTA, $5 \mathrm{mM} \mathrm{MgCl}_{2}, 0.1 \mathrm{mM}$ dithiothreitol (DTT) and protease inhibitor mixture. Proteins were electrophoretically resolved by $10-15 \%$ sodium dodecyl sulfate-polyacrylamide gel electrophoresis (SDS-PAGE), and immunoblotting was performed as previously described. Equal amounts of lysate protein were similarly electrophoretically resolved and electrophoretically transferred to a nitrocellulose membrane. Immunoreactivity was detected through sequential incubation with horseradish peroxidase-conjugated secondary antibody and enhanced chemiluminescence reagents. The antibodies used for immunoblotting were phospho-c-Jun, N-terminal kinase (JNK; Santa Cruz Biotechnology, Inc., Santa Cruz, CA, USA), Bcl-2 (Santa Cruz Biotechnology, Inc.) and phosphoAKT (Cell Signaling Technology, Inc., Cambridge, MA, USA).

Cellular fractionation. SH-SY5Y cells were resuspended in mitochondrial buffer $(210 \mathrm{mM}$ sucrose, $70 \mathrm{mM}$ mannitol,
$1 \mathrm{mM}$ EDTA and $10 \mathrm{mM}$ HEPES), broken by a 26-gauge needle and centrifuged at $700 \mathrm{x} g$ for $10 \mathrm{~min}$. The postnuclear supernatant was centrifuged at $10,000 \times \mathrm{g}$ for $30 \mathrm{~min}$. The pellet was used as the mitochondrial fraction, and the supernatant was used as the cytosolic fraction. Total proteins were obtained and subjected to western blotting.

Annexin $V$ assay. Apoptosis was assessed by a commercial Annexin V assay (Santa Cruz Biotechnology, Inc.), according to the manufacture's protocol. Annexin V content was determined by measuring fluorescence at excitation $488 \mathrm{~nm}$ and emission at 525/30 using a Guava easyCyte HT system (Millipore, Billerica, MA, USA).

Terminal deoxynucleotidyl transferase-mediated dUTP nick end labeling (TUNEL) assay. TUNEL analysis was performed to measure the degree of cellular apoptosis using an in situ ApoBrdU DNA fragmentation assay kit (BioVision, San Francisco, CA, USA), following the manufacturer's instructions.

DCFH-DA assay. SH-SY5Y cells were incubated in MEM (Hyclone Laboratories, Logan, UT, USA) containing $10 \mu \mathrm{M}$ 2',7'-dichlorodihydrofluorescein diacetate (H2-DCFDA) at $37^{\circ} \mathrm{C}$ for $30 \mathrm{~min}$. Cells were washed with phosphate-buffered saline (PBS) and lysed in the aforementioned lysis buffer. Cells were transferred to a clear 96-well plate, and fluorescent emission was measured at $515 \mathrm{~nm}$ on bottom read, with an excitation wavelength of $488 \mathrm{~nm}$, using a SpectraMax M2 instrument (Molecular Devices, Sunnyvale, CA, USA). SH-SY5Y cells were cultured on cover slips positioned in a 24-well plate. Cells were incubated in MEM (Hyclone Laboratories) containing $10 \mu \mathrm{M} \mathrm{H}$-DCFDA) at $37^{\circ} \mathrm{C}$ for $30 \mathrm{~min}$ and were then washed with PBS.

Mitochondrial transmembrane potential (MTP) assay. The change in MTP was evaluated by the cationic fluorescent indicator JC-1 (Molecular Probes, Eugene, OR, USA), which aggregates in intact mitochondria (red fluorescence) indicating high or normal MTP and low MTP when it remains in monomeric form in the cytoplasm (green fluorescence). SH-SY5Y cells were incubated in MEM containing $10 \mu \mathrm{M} \mathrm{JC}-1$ at $37^{\circ} \mathrm{C}$ for $30 \mathrm{~min}$, washed with PBS, and subsequently transferred to a clear 96-well plate. JC-1 aggregate fluorescent emission was measured at $583 \mathrm{~nm}$ with an excitation wavelength of $526 \mathrm{~nm}$, and JC-1 monomer fluorescence intensity was measured with an excitation and emission wavelength of 525 and $530 \mathrm{~nm}$, respectively, using a Guava easyCyte HT System (Millipore). SH-SY5Y cells were cultured on cover slips in a 24 -well plate, incubated in MEM containing $10 \mu \mathrm{m} \mathrm{JC}-1$ at $37^{\circ} \mathrm{C}$ for $30 \mathrm{~min}$ and then washed with PBS. Finally, cells were mounted with DakoCytomation fluorescent medium and visualized via fluorescence microscopy.

Statistical analysis. All data are expressed as mean \pm standard deviation (SD), and were compared using the Student's t-test and the ANOVA Duncan's test with the SAS statistical package (SAS, Cary, NC, USA). The results were considered statistically significant at ${ }^{*} \mathrm{P}<0.05$ or ${ }^{* *} \mathrm{P}<0.01$. 
A

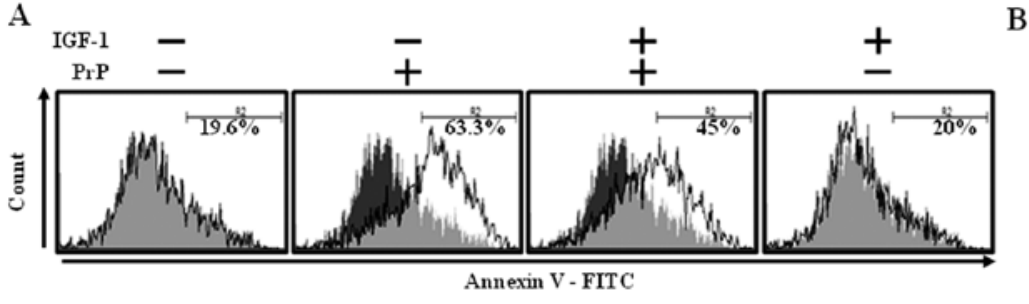

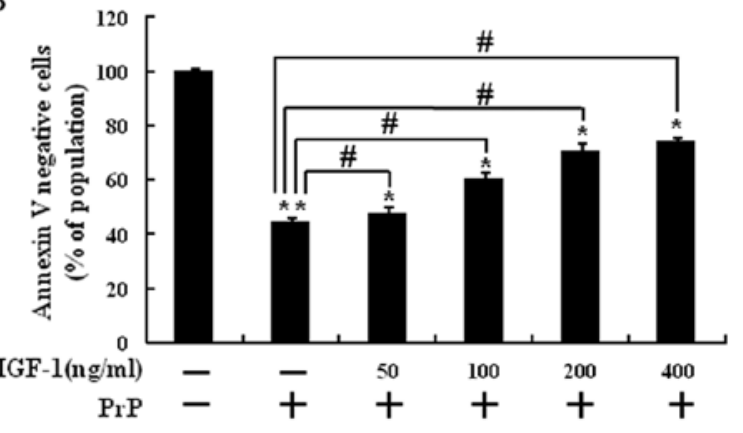

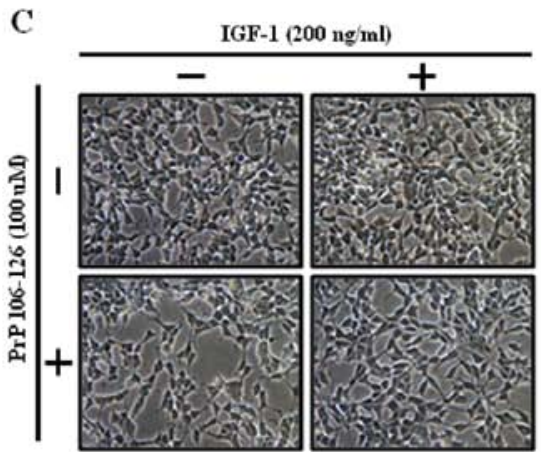

D

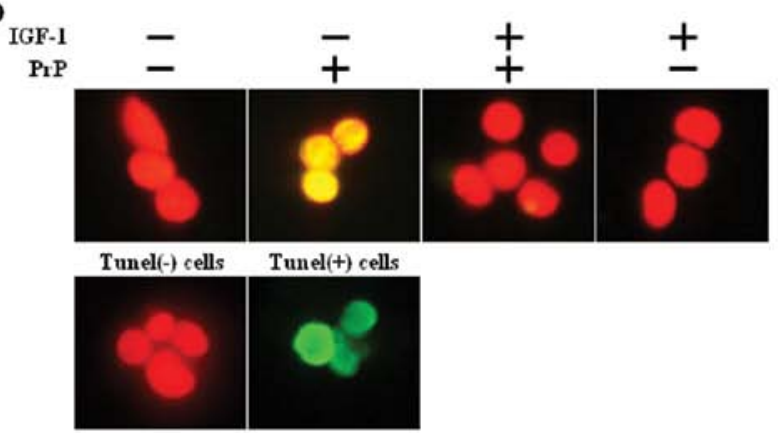

Figure 1. IGF-1 protects against PrP (106-126)-induced neuronal cell death. (A) SH-SY5Y neuronal cells were pretreated with IGF-1 (12 h) and then exposed to $100 \mu \mathrm{M} \operatorname{PrP}$ (106-126) for $24 \mathrm{~h}$. Cell viability was measured by Annexin V assay. (B) Bar graph indicates the averages of Annexin V-negative cells ${ }^{*} \mathrm{P}<0.05,{ }^{* *} \mathrm{P}<0.001$ vs. control; ${ }^{\prime} \mathrm{P}<0.01$ vs. PrP (106-126). (C) The treated cells were photographed by light microscopy (magnification, $\left.\mathrm{x} 100\right)$. Representative immunofluorescence images of TUNEL-positive (green) SH-SY5Y cells at $24 \mathrm{~h}$ after exposure to $100 \mu \mathrm{M}$ PrP (106-126) in the absence or presence of IGF-1 (12 h). The cells were counterstained with PI (red) to show all cell nuclei. Magnification, $\mathrm{x} 400$; scale bar, $100 \mu \mathrm{M}$.

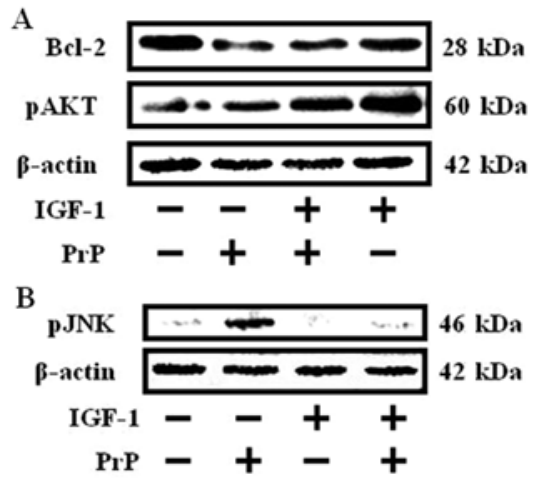

Figure 2. PrP (106-126)-mediated protein expression is suppressed by IGF-1 treatment. (A) SH-SY5Y neuronal cells were pretreated with IGF-1 (12 h) and then exposed to $100 \mu \mathrm{M} \operatorname{PrP}(106-126)$ for $18 \mathrm{~h}$. The treated cells were assessed for Bcl-2, p-AKT and $\beta$-actin production by western blot analysis. (B) The treated cells were also assessed for $\mathrm{p}$-JNK and $\beta$-actin production by western blot analysis.

\section{Results}

IGF-1 protects against $\operatorname{PrP}$ (106-126)-induced neuronal cell death. IGF-1 is neuroprotective in neurodegenerative diseases and is involved in Huntington's disease (20). To examine whether IGF-1 treatment protects neuronal cells from PrP (106-126)-mediated neurotoxic effects, SH-SY5Y cells were pretreated with IGF-1 before exposure to PrP (106-126). The protective effect of IGF-1 was determined by an Annexin V viability assay. SH-SY5Y cells were pretreated for $12 \mathrm{~h}$ with $200 \mathrm{ng} / \mathrm{ml}$ IGF-1 and then exposed to $100 \mu \mathrm{M}$ $\operatorname{PrP}$ (106-126) for $24 \mathrm{~h}$. Cells were responsive to $\operatorname{PrP}(106-126)$ treatment (43.7\% increase in Annexin V-positive cells) and IGF-1 had no effect on Annexin V assay results (Fig. 1A). As shown in Fig. 1B, IGF-1 at different concentrations $(50,100$, 200 and $400 \mathrm{ng} / \mathrm{ml}$ ) significantly attenuated the neurotoxicity induced by $24-\mathrm{h}$ exposure to $100 \mu \mathrm{M} \operatorname{PrP}(106-126)$. These results were confirmed by morphological observations of the treated cells using light microscopy (Fig. 1C). PrP (106-126)induced morphological changes were significantly alleviated by IGF-1. TUNEL assay results revealed that the concentration of fluorescent-fragmented nuclei increased in the $100 \mu \mathrm{M}$ PrP (106-126)-treated group compared to the $200 \mathrm{ng} / \mathrm{ml}$ IGF-1-pretreated group and the control group (Fig. 1D). These results suggest that IGF-1 promotes SH-SY5Y survival by preventing cell death induced by $\operatorname{PrP}(106-126)$.

$\operatorname{PrP}$ (106-126)-mediated protein expression is suppressed by IGF-1 treatment. $\operatorname{PrP}(106-126)$ impacts the activation of JNK and expression of the Bcl-2 protein (3), and IGF-1 induces upregulated expression of the antiapoptotic protein Bcl-2 and expression of a constitutively active Akt inhibited JNK activation $(5,21)$. To estimate the effect of IGF-1 on PrP (106-126) affected activation of JNK and expression of Bcl-2, SH-SY5Y cells were pretreated for $12 \mathrm{~h}$ with $200 \mathrm{ng} / \mathrm{ml}$ of IGF-1 and then exposed for $18 \mathrm{~h}$ to $100 \mu \mathrm{M}$ PrP (106-126). Western blot analyses revealed that the activation of JNK increased and decreased Bcl-2 expression in the $100 \mu \mathrm{M}$ PrP (106-126)-treated group compared to the IGF-1 

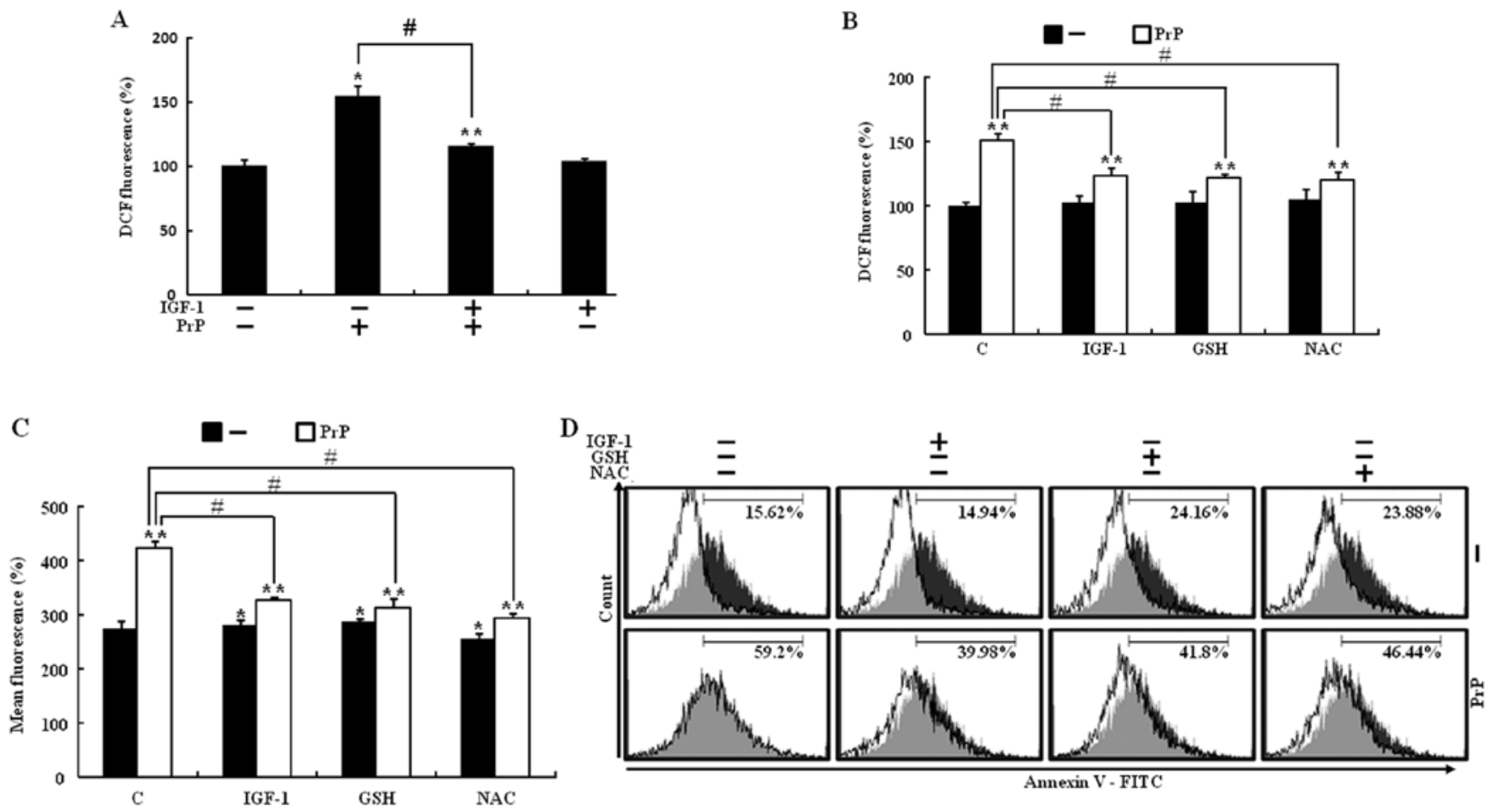

Figure 3. IGF-1 prevents PrP (106-126)-induced ROS generation. SH-SY5Y cells were pretreated with (A) IGF-1 or (B) antioxidant agents (800 $\mu$ M GSN and $4 \mathrm{mM} \mathrm{NAC}$ ) and then exposed to $100 \mu \mathrm{M} \operatorname{PrP}(106-126)$ for $24 \mathrm{~h}$. The treated cells were used for measuring ROS release with the DCFH-DA assay as described in Materials and methods. ${ }^{*} \mathrm{P}<0.05 ;{ }^{* *} \mathrm{P}<0.001$ vs. control, ${ }^{\prime \prime} \mathrm{P}<0.01$ vs. PrP (106-126). (C) The treated cells also were used for measuring ROS release with the DCFH-DA assay as described by flow cytometry. ${ }^{*} \mathrm{P}<0.05,{ }^{* *} \mathrm{P}<0.001$ vs. control; ${ }^{*} \mathrm{P}<0.01$ vs. PrP (106-126). (D) SH-SY5Y neuronal cells were pretreated with IGF-1 (12 h) or antioxidant agents ( $800 \mu \mathrm{M}$ GSN and $4 \mathrm{mM} \mathrm{NAC})$ and then exposed to $100 \mu \mathrm{M}$ PrP (106-126) for $24 \mathrm{~h}$. Cell viability was measured by Annexin V assay.

$(200 \mathrm{ng} / \mathrm{ml})$ pretreated group and the control group (Fig. 2B). However, IGF-1 treatment inhibited PrP (106-126)-induced activated JNK and inhibited Bcl-2 expression in SH-SY5Y cells (Fig. 2). In addition, IGF-1 enhanced phosphorylation of AKT. However, PrP (106-126) had no effect on western blotting results (Fig. 2A). These results suggest that IGF-1 inhibits PrP (106-126)-induced activation of JNK and decreases both $\mathrm{Bcl}-2$ expression and AKT activation.

IGF-1 prevents $\operatorname{PrP}$ (106-126)-induced ROS generation. IGF-1 reduces oxidative stress in neuronal cells (22). Furthermore, $\operatorname{PrP}(106-126)$ induces cell death as a result of its ability to regulate intracellular ROS production (23). To investigate whether IGF-1 treatment had a neuroprotective effect as a result of inhibited ROS generation in $\operatorname{PrP}$ (106-126)-induced neuronal cell death, SH-SY5Y cells were pretreated for $12 \mathrm{~h}$ with $200 \mathrm{ng} /$ $\mathrm{ml}$ of IGF-1 and then exposed to $100 \mu \mathrm{M} \operatorname{PrP}$ (106-126) for $24 \mathrm{~h}$. A DCFH-DA assay was carried out to ascertain ROS generation. The addition of IGF-1 did not change the level of DCFDA intensity, however, IGF-1 inhibited ROS production in PrP (106-126)-induced increased ROS production (Fig. 3A). To determine whether IGF-1 treatment had a neuroprotective effect by decreasing ROS production in $\operatorname{PrP}$ (106-126)-induced neuronal cell death, SH-SY5Y cells were pretreated with IGF-1, antioxidant agents (GSH and NAC), and then exposed to $\operatorname{PrP}$ (106-126). Following exposure to $100 \mu \mathrm{M} \operatorname{PrP}$ (106-126), DCF fluorescence intensity in SH-SY5Y cells increased significantly to $150 \%$ of the control value, whereas IGF-1 $(200 \mathrm{ng} / \mathrm{ml})$ or antioxidants $(800 \mu \mathrm{M} \mathrm{GSH}$ or $4 \mathrm{mM} \mathrm{NAC})$ led to a prominent decrease in DCF fluorescence intensity (Fig. 3B and C). To investigate whether decreased ROS production had a protective effect on $\operatorname{PrP}(106-126)$ induced neuronal cell death, an Annexin V assay was used. Treatment with IGF-1 and both antioxidant agents inhibited PrP (106-126)-induced neuronal cell death (Fig. 3D). The results suggested that PrP (106-126)-induced neuronal cell death via increased ROS generation and IGF-1 treatment had a neuroprotective effect by decreasing ROS production.

$\operatorname{PrP}$ (106-126)-induced mitochondrial dysfunction can be suppressed by IGF-1. Previous studies have shown that mitochondrial dysfunction increases oxidative stress and PrP (106-126)-induced neurotoxicity through induced mitochondrial dysfunction $(3,8)$. To determine whether IGF-1 treatment had an antioxidant effect by prevention of mitochondrial dysfunction in $\operatorname{PrP}$ (106-126)-induced neuronal cell death, an MTP assay was conducted. PrP (106-126)-treated cells showed increased JC-1 monomers, indicating low MTP values, while IGF-1 treatment reduced $\operatorname{PrP}(106-126)$-induced JC-1 monomers, indicating high MTP values (Fig. 4A). Consistent with these results, fluorescence microscopy also showed that IGF-1 could markedly reduce the green fluorescence (JC-1 monomer form, gray) of PrP (106-126)-induced neuronal cell death, and the negative control cells and IGF-1treated cells showed red fluorescence (JC-1 aggregate form, white) (Fig. 4B). Since it has been previously established that the Bax protein is associated with the mitochondrial apoptotic pathway (24), we examined the effect of IGF-1 on 

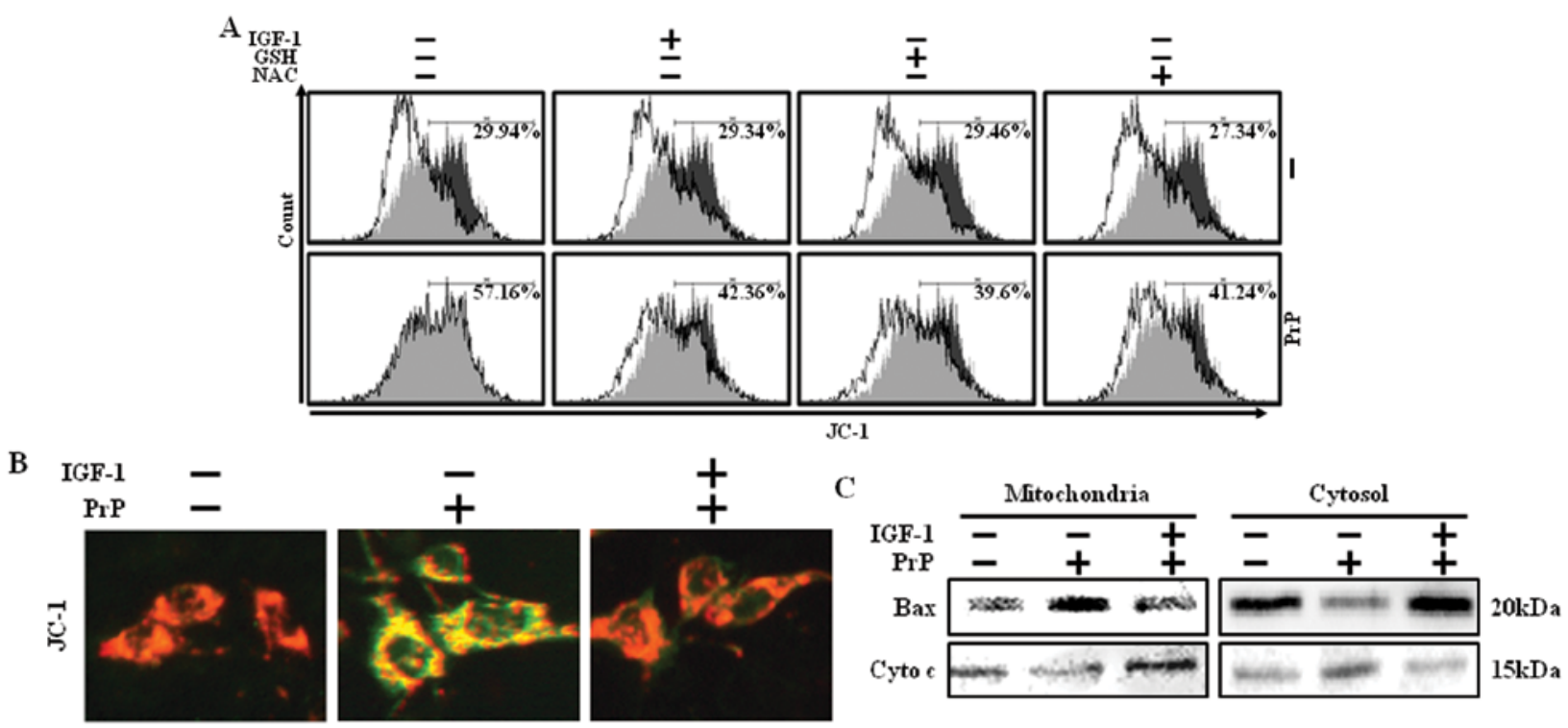

Figure 4. PrP (106-126)-induced mitochondrial dysfunction can be suppressed by IGF-1. (A) SH-SY5Y cells were pretreated with IGF-1 or antioxidant agents ( $800 \mu \mathrm{M} \mathrm{GSN}$ and $4 \mathrm{mM} \mathrm{NAC)}$ and then exposed to $100 \mu \mathrm{M} \mathrm{PrP} \mathrm{(106-126)} \mathrm{for} 24 \mathrm{~h}$. The treated cells were measured for JC-1 mono form (green) by flow cytometry. (B) The treated cells were also photographed using a fluoroscope. The red fluorescence intensity was measured at $530 \mathrm{~nm}$ (emission of JC-1 monomeric form) when excited at $490 \mathrm{~nm}$. (C) Cells were homogenized in a mitochondrial buffer, as described in Materials and methods. The separation of cytosol and mitochondrial extracts was analyzed by western blotting using antibodies against cytochrome $c$ and the Bax protein.

PrP (106-126)-induced Bax translocation and cytochrome $c$ release. PrP (106-126)-induced translocation of Bax into mitochondria and cytochrome $c$ release to the cytosol in SH-SY5Y cells. By contrast, PrP (106-126)-induced translocation of Bax and cytochrome $c$ release was blocked when pretreated with IGF-1 (Fig. 4C). Collectively, these results indicate that IGF-1 protects against prion peptide induced-cell death in neuronal cells by blocking Bax translocation.

\section{Discussion}

The synthetic peptide PrP (106-126) is composed of human prion protein (PrP) amino acid residues 106-126 (25). $\operatorname{PrP}$ (106-126) maintains the neurotoxic properties of the entire pathological PrPSc and is widely used as a reasonable model to study the mechanism of prion disorders (25). However, the mechanism by which this peptide induces cell death in neuronal cells is not fully understood. Most of these diseases (including Creutzfeldt-Jakob disease, scrapie and Alzheimer's disease) are caused by accumulation of PrPSc (26). Therefore, the accumulation of PrPSc has been postulated to be a solitary inducer of disease onset due to neuronal cell death (26).

IGF-1 is a multifunctional peptide that is structurally similar to insulin and has neuroprotective and antiapoptotic properties (16). The IGF-I pro-survival signaling pathway is altered in neurodegenerative diseases including Huntington's disease and spinocerebellar ataxia (19). Furthermore, scrapie infection affects the expression, binding affinity and signal transduction mediated by IGF-1R in neuroblastoma cells (27). However, the protective effect of IGF-1 on PrP (106-126)induced neuronal cells has yet to be fully clarified.

We considered whether IGF-1 could exert a neuroprotective effect on prion disease, and this prompted our examination of the possible beneficial effects of IGF-1 on PrP (106-126)- induced neuronal cell damage. Our results demonstrate that IGF-1 prevents prion-induced neuronal cell death and neurotoxicity in SH-SY5Y cells pretreated with IGF-1 for $12 \mathrm{~h}$ prior to 24 h exposure to $\operatorname{PrP}$ (106-126) (Fig. 1).

PrP (106-126) induces neuronal cell death by activating JNK protein phosphorylation and decreasing the level of the Bcl-2 protein $(21,28)$. JNK, an established mediator of stress-induced apoptosis, is involved in the neurodegenerative processes in neurodegenerative disorders (29), and represents a potential therapeutic target for blockage of apoptosis induced by $\operatorname{PrP}(106-126)$ (11). We demonstrated the involvement of IGF-1 action on PrP (106-126)-induced phosphorylated JNK and decreased $\mathrm{Bcl}-2$ protein expression by western blotting. PrP (106-126) induced the phosphorylation of JNK and decreased Bcl-2 expression; these actions were inhibited by IGF-1 (Fig. 2).

Similarly, previous studies have demonstrated that activation of glycogen synthase kinase $3-\beta$ (GSK-3 $\beta$ ) precedes the activation of JNK and that this effect contributes to apoptotic signaling (16). Markedly, the activation of GSK-3 $\beta$ is an important mediator of prion peptide-induced neurodegeneration and neuronal cell survival in neurodegenerative disorders is mediated by JNK inactivation via phosphorylated AKT dependent GSK-3 $\beta$ inhibition $(16,30)$. In addition, the protective effects of IGF-1 are mediated by pAKT expression in neuronal cells (15). Our results indicate that the inhibition of $\operatorname{PrP}(106-126)$-induced JNK activation is a downstream event of AKT/GSK-3 $\beta$ signaling and may add more weight to GSK-3 $\beta$ blockage in the treatment of prion disorders.

Studies of neurodegenerative diseases have reported physical disruption of the mitochondria (31). In addition, some recent reports have shown that $\operatorname{PrP}(106-126)$ induces neuronal cell death by mitochondrial disruption in neuroblastoma cells and mitochondrial disruption by activated JNK and Bax trans- 
location (32). Therefore, $\operatorname{PrP}$ (106-126)-induced mitochondrial disruption may possibly be the cause of oxidative stress in neuronal cells. Oxidative stress results from increased content of ROS and is the main source of the neuronal cell death; ROS are particularly high in neurodegenerative disorders. Increased ROS production by mitochondrial dysfunction ultimately causes cell death. These results suggest that the increased oxidative stress is central to the pathogenesis of prion diseases.

This study has shown that PrP (106-126)-induced intracellular ROS production changed by IGF-1 treatment, and was investigated by antioxidant agents (GSN and NAC) (Fig. 3).

The use of antioxidant agents demonstrated a protective effect against $\operatorname{PrP}$ (106-126)-induced mitochondrial disruption by inhibiting mitochondrial dysfunction. This protective effect indicates that IGF-1 treatment may attenuate PrP (106-126)-induced ROS generation via inhibition of mitochondrial dysfunction. Furthermore, PrP (106-126) induces mitochondrial dysfunction by Bax translocation (33). Bax translocation is a critical event in neuronal apoptosis. Thus, we considered whether IGF-1 has a neuroprotective effect on prion disease by blocking Bax translocation. The present results show that IGF-1 blocks PrP (106-126)-induced Bax translocation (Fig. 4C).

In summary, IGF-1 inhibits PrP (106-126)-induced ROS production and consequently neuronal cell death by preventing mitochondria dysfunction and Bax translocation to mitochondria. The observation that IGF-1 inhibits Bax translocation by preventing mitochondria dysfunction may have clinical benefits for neurodegenerative chemotherapy in patients with diseases such as prion disease.

\section{Acknowledgements}

This study was supported by the Cooperative Research Program for Agriculture Science and Technology Development (PJ907116) in the Rural Development Administration, Republic of Korea.

\section{References}

1. Nair RR and Johnson JK: Prions and neuro degenerative diseases (Review). Afr J Biotechnol 10: 2366-2374, 2011.

2. Clarke AR, Jackson GS and Collinge J: The molecular biology of prion propagation. Philos Trans R Soc Lond B Biol Sci 356 : 185-195, 2001.

3. O'Donovan CN, Tobin D and Cotter TG: Prion protein fragment PrP-(106-126) induces apoptosis via mitochondrial disruption in human neuronal SH-SY5Y cells. J Biol Chem 276: 43516-43523, 2001.

4. Pan YH, Wang YC, Zhang LM and Duan SR: Protective effect of edaravone against PrP106-126-induced PC12 cell death J Biochem Mol Toxicol 24: 235-241, 2010.

5. Logan DC: The mitochondrial compartment. J Exp Bot 57: 1225-1243, 2006.

6. Choi HS, Oh JM, Sin HY, et al: Mitochondrial dysfunction via differential modulation of mitochondrial fusion/fission proteins in the brains of scrapie-infected mice. Prion 4: 174, 2010.

7. Gross A, McDonnell JM and Korsmeyer SJ: BCL-2 family members and the mitochondria in apoptosis. Gene Dev 13 1899-1911, 1999.

8. Choi SI, Ju WK, Choi EK, et al: Mitochondrial dysfunction induced by oxidative stress in the brains of hamsters infected with the 263 K scrapie agent. Acta Neuropathol 96: 279-286, 1998.

9. Sagara Y, Ishige K, Tsai C and Maher P: Tyrphostins protect neuronal cells from oxidative stress. J Biol Chem 277: 36204-36215, 2002.
10. Wang MS, Boddapati S, Emadi S and Sierks MR: Curcumin reduces alpha-synuclein induced cytotoxicity in Parkinson's disease cell model. BMC Neurosci 11: 57, 2010.

11. Evans JL, Goldfine ID, Maddux BA and Grodsky GM: Are oxidative stress-activated signaling pathways mediators of insulin resistance and beta-cell dysfunction? Diabetes 52: 1-8, 2003.

12. Simon HU, Haj-Yehia A and Levi-Schaffer F: Role of reactive oxygen species (ROS) in apoptosis induction. Apoptosis 5: 415-418, 2000.

13. Leshem Y, Seri L and Levine A: Induction of phosphatidylinositol 3-kinase-mediated endocytosis by salt stress leads to intracellular production of reactive oxygen species and salt tolerance. Plant J 51: 185-197, 2007.

14. Kang BPS, Frencher S, Reddy V, Kessler A, Malhotra A and Meggs LG: High glucose promotes mesangial cell apoptosis by oxidant-dependent mechanism. Am J Physiol Renal Physiol 284: F455-F466, 2003.

15. Davila D and Torres-Aleman I: Neuronal death by oxidative stress involves activation of FOXO3 through a two-arm pathway that activates stress kinases and attenuates insulin-like growth factor I signaling. Mol Biol Cell 19: 2014-2025, 2008.

16. Wang L, Yang HJ, Xia YY and Feng ZW: Insulin-like growth factor 1 protects human neuroblastoma cells SH-EP1 against $\mathrm{MPP}^{+}$-induced apoptosis by AKT/GSK- $3 \beta / \mathrm{JNK}$ signaling. Apoptosis 15: 1470-1479, 2010.

17. Trejo JL, Carro E, Garcia-Galloway E and Torres-Aleman I: Role of insulin-like growth factor I signaling in eurodegenerative diseases. J Mol Med (Berl) 82: 156-162, 2004.

18. Zhong $\mathrm{J}$ and Lee WH: Hydrogen peroxide attenuates insulin-like growth factor-1 neuroprotective effect, prevented by minocycline. Neurochem Int 51: 398-404, 2007.

19. Laviola L, Natalicchio A, Perrini S and Giorgino F: Abnormalities of IGF-I signaling in the pathogenesis of diseases of the bone, brain, and fetoplacental unit in humans. Am J Physiol Endocrinol Metab 295: E991-E999, 2008.

20. Saleh N, Moutereau S, Durr A, et al: Neuroendocrine disturbances in Huntington's disease. PLoS One 4: e4962, 2009.

21. Pugazhenthi S, Nesterova A, Sable C, et al: Akt/protein kinase B up-regulates Bcl-2 expression through cAMP-response elementbinding protein. J Biol Chem 275: 10761-10766, 2000.

22. Gustafsson H, Soderdahl T, Jonsson G, Bratteng JO and Forsby A: Insulin-like growth factor type 1 prevents hyperglycemiainduced uncoupling protein 3 down-regulation and oxidative stress. J Neurosci Res 77: 285-291, 2004.

23. Pietri M, Caprini A, Mouillet-Richard S, et al: Overstimulation of PrPC signaling pathways by prion peptide 106-126 causes oxidative injury of bioaminergic neuronal cells. J Biol Chem 281: 28470-28479, 2006.

24. Nechushtan A, Smith CL, Lamensdorf I, Yoon SH and Youle RJ: Bax and Bak coalesce into novel mitochondria-associated clusters during apoptosis. J Cell Biol 153: 1265-1276, 2001.

25. Seo JS, Seol JW, Moon MH, Jeong JK, Lee YJ and Park SY: Hypoxia protects neuronal cells from human prion protein fragment-induced apoptosis. J Neurochem 112: 715-722, 2010.

26. Sakudo A and Ikuta K: Prion Protein functions and dysfunction in prion diseases. Curr Med Chem 16: 380-389, 2009.

27. Ostlund $\mathrm{P}$, Lindegren $\mathrm{H}$, Pettersson $\mathrm{C}$ and Bedecs $\mathrm{K}$ : Up-regulation of functionally impaired insulin-like growth factor-1 receptor in scrapie-infected neuroblastoma cells. J Biol Chem 276: 36110-36115, 2001.

28. Carimalo J, Cronier S, Petit G, et al: Activation of the JNK-c-Jun pathway during the early phase of neuronal apoptosis induced by PrP106-126 and prion infection. Eur J Neurosci 21: 2311-2319, 2005.

29. Hunot S, Vila M, Teismann P, et al: JNK-mediated induction of cyclooxygenase 2 is required for neurodegeneration in a mouse model of Parkinson's disease. Proc Natl Acad Sci USA 101: 665-670, 2004.

30. Perez M, Rojo AI, Wandosell F, Diaz-Nido J and Avila J: Prion peptide induces neuronal cell death through a pathway involving glycogen synthase kinase 3. Biochem J 372: 129-136, 2003.

31. Szegezdi E, Logue SE, Gorman AM and Samali A: Mediators of endoplasmic reticulum stress-induced apoptosis. EMBO Rep 7: 880-885, 2006.

32. Corsaro A, Thellung S, Villa V, et al: Prion protein fragment 106-126 induces a p38 MAP kinase-dependent apoptosis in SH-SY5Y neuroblastoma cells independently from the amyloid fibril formation. Ann NY Acad Sci 1010: 610-622, 2003.

33. Jeong JK, Moon MH, Lee YJ, Seol JW and Park SY: Melatonininduced autophagy protects against human prion protein-mediated neurotoxicity. J Pineal Res: Jan 30, 2012 (Epub ahead of print). 